\title{
Refinement and application of a coupled tidal prism model with HSPF for managing bacterial water quality impairment in a coastal watershed
}

\author{
R. S. Sobel ${ }^{1}$, H. S. Rifai ${ }^{1} \&$ T. M. Petersen ${ }^{2}$ \\ ${ }^{I}$ Civil and Environmental Engineering, University of Houston, USA \\ ${ }^{2}$ CDM Smith, Houston, TX, USA
}

\begin{abstract}
Coastal water quality is strongly influenced by tidal fluctuations and water chemistry, with an increased likelihood of bacterial water quality impairment due to urbanization. To address these challenges, there is a need for computationally and financially practical models with sufficient rigor to simulate the hydrodynamics and bacteria sources in relatively small, shallow waterways with upstream freshwater dominance and tidal influence. This study presents a coupled Tidal Prism Model (TPM) and watershed runoff model (HSPF) for a tidally influenced and impaired stream near Houston, Texas, USA. The TPM accounts for loading from tidal exchange, runoff, point sources, and bacterial decay using an hourly time step. The linked models were calibrated to flow and E. Coli (for HSPF), and salinity and enterococci data (for the TPM). When further refined, the model captures the "order of magnitude" of natural variability using a dynamic net decay rate. To assess the effectiveness of management strategies to improve water quality, the coupled model is applied for various scenarios for wastewater treatment plant bacterial effluent controls and runoff reduction via low impact development. Strategies focusing on both point and nonpoint source reduction are necessary to improve water quality through the length of the waterway. The simulation tool employed here is extremely useful and can be readily adapted for other inland tidally influenced water bodies, thereby, enabling cost-effective watershed planning at multiple resolutions.
\end{abstract}

Keywords: indicator bacteria, hydrological modeling, water quality, watershed management. 


\section{Introduction}

Inland coastal waterways often contain exclusively freshwater upstream but transition to tidal influence before draining to a bay or other salt water system. Assessing and managing water quality in these areas is more challenging due to fluctuations in salinity and flow direction [1]. Addressing bacterial impairment has an additional complication because E.coli is the indicator species for freshwater while enterococci is preferred in tidal waters. Complex three dimensional models like EFDC are valuable tools but impractical for relatively shallow and narrow inland waters experiencing tidal influence [2-4]. Sobel et al. [5] developed a coupled Tidal Prism Model (TPM) with Hydrologic Simulation ProgramFORTRAN (HSPF) to simulate both hydrodynamics and runoff loading. The coupled TPM-HSPF model is rigorous yet requires relatively minimal data input as the system can be represented in one dimension. Their TPM-HSPF model is the first to integrate tidal and watershed modelling at a sub-daily time step that reflect recent findings in the literature on the variability time scales for bacterial water quality [6-9].

Flood and ebb tides result in the alternate storage and drainage of a given volume of water known as the tidal prism. The TPM was first developed by Ketchum [10] to represent fresh and saltwater mixing as occurring within waterbody segments, or reaches, instead of through whole system. Dyer and Taylor [11] updated the TPM to include point source and tributary inflows and allowance of incomplete mixing. The TPM has since undergone multiple refinements and has been applied for various objectives such as total maximum daily load (TMDL) determinations [3, 12-14].

Bacteria levels can change by multiple orders of magnitude in just a few hours, but tidal modelling is generally executed at a much coarser resolution [6-9]. In this paper, the original TPM-HSPF model is refined to better capture natural bacteria variability using a dynamic decay rate at an hourly time step. Good agreement between the observed and modelled $90^{\text {th }}$ percentile concentrations is achieved without sacrificing geometric mean agreement to which the original model was calibrated. Management scenarios are evaluated using the refined model to support best management practices (BMPs) in achieving applicable water quality standards in the impaired waterbody.

\section{Dickinson Bayou TPM-HSPF modeling}

\subsection{Study area}

Dickinson Bayou is a $100 \mathrm{mi}^{2}$ coastal prairie tidal stream located southeast of Houston, Texas (Figure 1). The tidal boundary of the bayou is also depicted in Figure 1. During the period for model simulation, grass and shrubland comprised almost half of the watershed area, followed by forested land at $25 \%$, and developed land at $15 \%$ (concentrated in downstream sub-watersheds). The remaining area was covered by cultivated land, wetlands, bare/transitional land, and open water. 
Elevated indicator bacteria levels have been a consistent problem in the waterway with observed concentrations of $E$. coli reaching 24,192 colony forming units (CFU)/dL, and enterococci concentrations up to 25,200 CFU/dL.

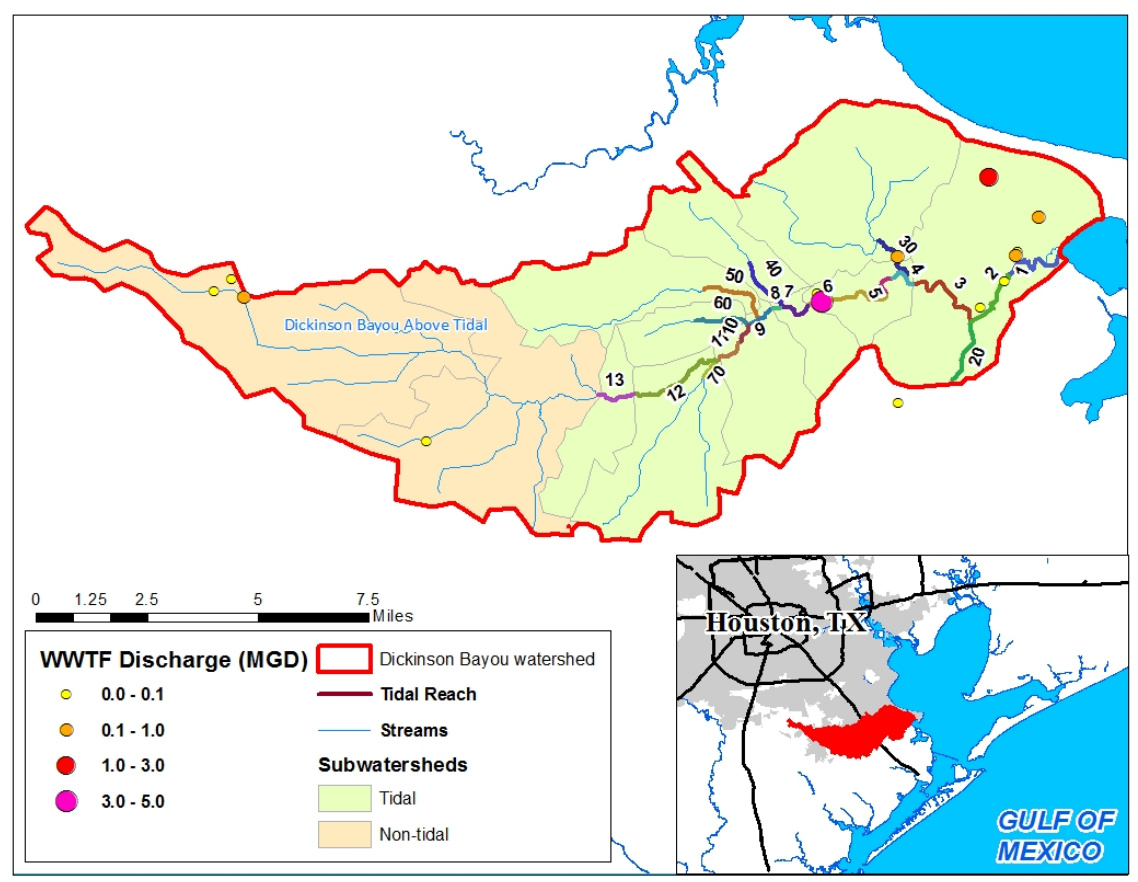

Figure 1: The Dickinson Bayou study watershed.

\subsection{TPM-HSPF model set-up}

The TPM-HSPF model accounts for all known indicator bacteria sources in the watershed including wastewater treatment plants (WWTPs), sanitary sewer overflows (SSOs), stormwater runoff, leaking septic systems, and unregulated discharges.

The TPM is run using an Excel interface and is calculated as a mass balance for a given reach; defined as the hourly storage difference after accounting for gain or loss of flow due to tidal exchange (from reaches located upstream or downstream). Tidal exchange and net first-order decay (loosely defined as the sum of all bacterial processes including die-off rates, settling, re-suspension and regrowth) also represent the two potential sinks of enterococci. The model was developed for Dickinson Bayou and run from June 6, 1999 to November 11, 2001. Further details on model development and TPM-HSPF integration can be found in Sobel et al. [5]. 


\subsection{Model refinement}

\subsubsection{E. coli to Enterococci conversion}

HSPF indicator bacteria output is in concentration of E. coli, however the TPM uses Enterococci. The original model performed conversion from $E$. coli to Enterococci based on the ratio between the State of Texas' geometric mean criteria for each indicator. Ratios between these indicators are highly site specific so the refined model was updated to reflect the specific conditions of Dickinson Bayou. The updated conversion ratio was computed from the average ratio between observed indicators where coincident samples existed and was found to be 0.656 which is higher than 0.278 , the value that represents the ratio of standards.

\subsubsection{Time variant decay rate}

In the original model, reaches were calibrated to the geometric mean of observations when a water quality monitoring (WQM) station was present. Both laboratory and field experiments display indicator bacteria decay rates than span several orders of magnitude and are influenced by many factors such as sunlight, temperature, and salinity [9, 15-17]. To account for such fluctuations, the refined model incorporated a dynamic decay rate based on temperature (4 categories), time of day (6 categories), and salinity ( 5 categories) for a total of 120 unique decay rate values ranging between $-0.05-1.5 \mathrm{hr}^{-1}$. The negative lower bound reflects a "night-time" condition where re-growth is likely.

\section{Results and discussion}

\subsection{Time variant decay rate refinement}

While the original model accurately captures observed geometric mean concentrations, the refined model performs better in reflecting the range of observed concentrations. Figure 2(a) depicts the geometric mean of all hourly concentrations for each tidal reach in the original model, refined model, and for observed data (where WQM stations exist). The $90^{\text {th }}$ percentile hourly concentration in each tidal reach is found in Figure 2(b) for the original model, refined model, and observed data. The refined model is in better agreement with observed conditions in all model reaches (1-13) and tributaries (20-70) where sampling data is available - See Figure 1.

Figure 3 demonstrates the improved performance of the refined model at an hourly resolution. Sample output for Reaches 7, 8 and 11 compare hourly concentrations in the original and refined models to observed enterococci data. The decay rate and indicator bacteria ratio refinements result in a wider range of model output that is more reflective of natural fluctuation in observed conditions.

The root mean squared error (RMSE) in observed and modelled values was calculated for each reach where a WQM station was present. As seen in Table 1, the refined model is actually in better agreement with observed conditions for both metrics. When removing the large errors in Tributaries 30 and 40, the original 

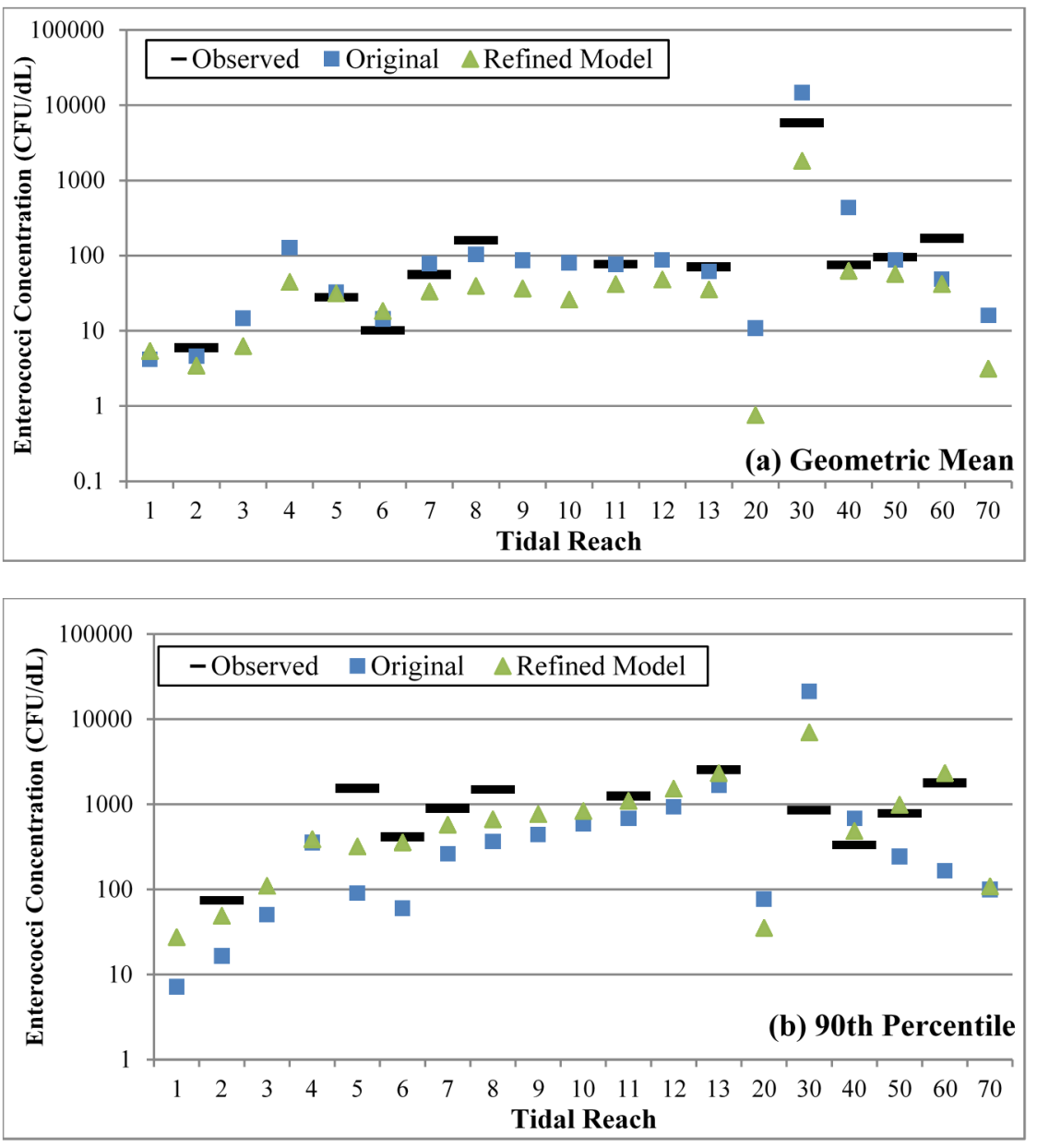

Figure 2: Geometric mean and 90th percentile concentrations in observed data, original model, and refined model.

model has only a slightly smaller RMSE for geometric mean, and the refined model is still a better fit for the $90^{\text {th }}$ percentile concentrations

\subsection{Watershed management scenarios}

Watershed management strategies were simulated to address both point and nonpoint source inputs. Non point sources reductions were based on literature values for the potential impacts of low impact development [18-20]. Table 2 details the management scenarios performed in the refined model. Figure 4 illustrates the geometric mean concentration in each mainstem tidal reach (1-13) for each of the four management strategies as well as the refined model geometric mean before management. 

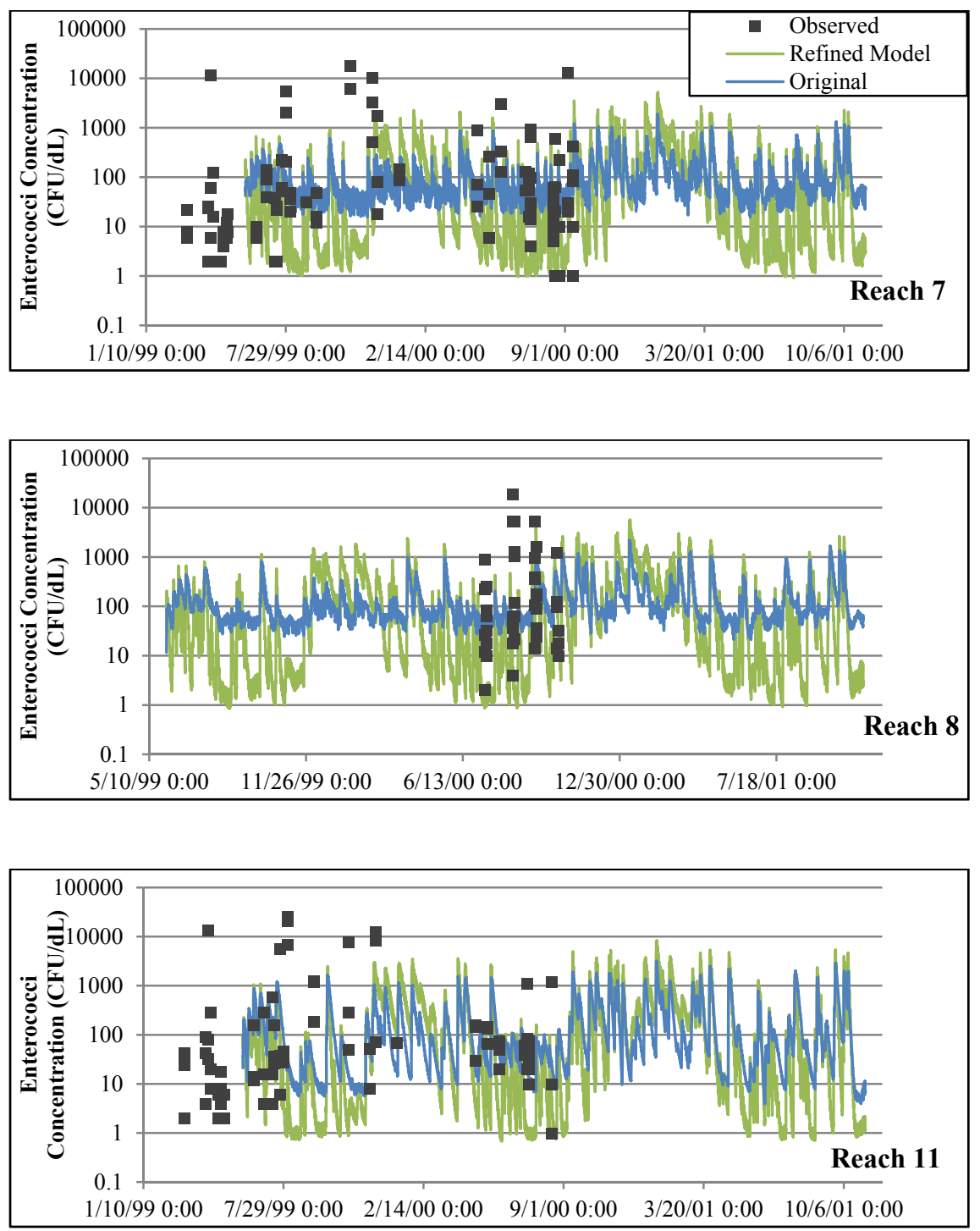

Figure 3: Time series comparison of observed versus original and refined model output in Reaches 7, 8, and 11.

The success of each scenario is assessed through achievement of the geometric mean standard of $35 \mathrm{CFU} / \mathrm{dL}$ in all mainstem reaches. None of the first three strategies, which address only one type of source, achieve the standard in all tidal reaches. Realistic reduction strategies must address both types of sources. The combined strategy produces geometric mean enterococci concentrations below 35 $\mathrm{CFU} / \mathrm{dL}$ in all 13 mainstem reaches. This strategy targets the high volumes and 
Table 1: Average absolute percent difference in each model output from observed conditions.

\begin{tabular}{|c|c|c|c|}
\hline \multirow{2}{*}{ Model Parameter } & \multicolumn{2}{|c|}{ RMSE (CFU/dL) } \\
\cline { 3 - 4 } & 11 WQM stations & 9 WQM stations \\
\hline \multirow{2}{*}{$\begin{array}{c}\text { Geometric } \\
\text { mean }\end{array}$} & Refined & 1212 & 63 \\
\cline { 2 - 4 } & Original & 2680 & 46 \\
\hline $\begin{array}{c}90^{\text {th }} \\
\text { Percentile }\end{array}$ & Refined & 1917 & 552 \\
\cline { 2 - 4 } & Original & 6165 & 946 \\
\hline
\end{tabular}

Table 2: Description of management scenarios.

\begin{tabular}{|c|c|c|c|}
\hline Strategy & Reduction & Non-point sources & Point Sources \\
\hline A & $25 \%$ & HSPF flows & \\
\hline B & $25 \%$ & & WWTP and SSO loads \\
\hline C & $25 \%$ & HSPF loads & \\
\hline \multirow{3}{*}{ Combined } & $20 \%$ & Reach 13 flow and loads & \\
\cline { 2 - 4 } & $5 \%$ & Reach 1-12 flows and loads & \\
\cline { 2 - 4 } & $50 \%$ & & SSO flows (Reach 30) \\
\hline
\end{tabular}

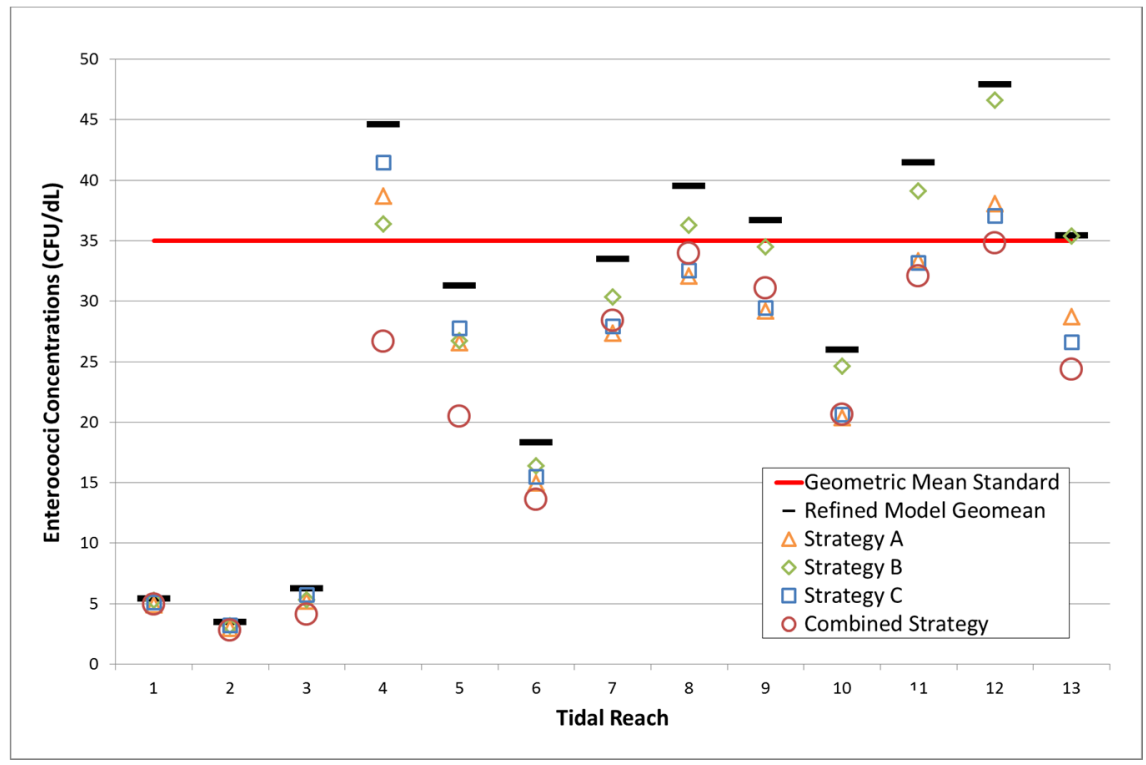

Figure 4: Water quality management scenarios. 
frequencies of SSOs that were observed in Reach 30 as well as high levels of runoff in upstream freshwater. A focus on the most critically impaired portions of the watershed means that only minimal reductions $(5 \%)$ are needed in the remainder of the watershed. These findings differ substantially from the original model (not pictured) which predicted much larger percent reductions in order to achieve the geometric mean standard [5]. Finally, no management strategies (in either the refined or original models) were able to reduce the rate of exceedance of the single sample criterion in all reaches (no more than $25 \%$ of samples above $89 \mathrm{CFU} / \mathrm{dL}$ ).

\section{Conclusions}

The coupled TPM-HSPF model is an effective tool for assessing bacterial water quality impairment in narrow and spatially homogenous waterways with downstream tidal influence. Refinements in indicator bacteria conversion and time variant decay rate substantially improved performance of the model. The refined TPM-HSPF model output provides a more accurate representation of observed conditions at an hourly time step and across the entire simulation period.

These updates serve to increase confidence in the accuracy of watershed management strategies. They reveal that less costly or invasive measures may be sufficient to improve bacterial water quality. The refined model can be employed in future work to examine short term impacts of large runoff events or WWTP non-compliance events.

\section{References}

[1] Salomon, J.C. and M. Pommepuy, Mathematical Model of Bacterial Contamination of the Morlaix Estuary (France). Water Research, 1990. 24(8): pp. 983-994.

[2] Liu, Z., et al., Hydrodynamic Modeling of St. Louis Bay Estuary and Watershed Using EFDC and HSPF. Journal of Coastal Research, 2008: pp. 107-116.

[3] Kuo, A.Y., et al., A tidal prism water quality model for small coastal basins. Coastal Management, 2005. 33(1): pp. 101-117.

[4] Sisson, G.M., et al., Developing a cost-effective methodology to manage Fecal Coliform loading in shellfish harvesting areas of upper Chesapeake Bay, Maryland. 2008.

[5] Sobel, R.S., H.S. Rifai, and C.M. Petersen, Linking a Tidal Prism Model with HSPF for Simulating Indicator Bacteria in a Coastal Watershed. JAWRA, 2015. Submitted.

[6] Bougeard, M., et al., Modeling of Escherichia coli Fluxes on a Catchment and the Impact on Coastal Water and Shellfish Quality. Journal of the American Water Resources Association, 2011. 47(2): pp. 350-366.

[7] de Brauwere, A., N.K. Ouattara, and P. Servais, Modeling Fecal Indicator Bacteria Concentrations in Natural Surface Waters: A Review. Critical 
Reviews in Environmental Science and Technology, 2014. 44(21): pp. 2380-2453.

[8] Wang, T., et al., Fecal Coliform Modeling in Small Coastal Waters Using a Linked Watershed and Tidal Prism Water Quality Model: A Preliminary Study in Jarrett Bay, North Carolina. Watershed Management to Meet Water Quality Standards and Emerging TMDL Conference, 2005: pp. 373379.

[9] Desai, A.M. and H.S. Rifai, Escherichia coli Concentrations in Urban Watersheds Exhibit Diurnal Sag: Implications for Water-Quality Monitoring and Assessment. Journal of the American Water Resources Association, 2013. 49(4): pp. 766-779.

[10] Ketchum, B.H., The exchanges of fresh and salt waters in tidal estuaries. Journal of Marine Research, 1951. 10(1): pp. 18-38.

[11] Dyer, K.R. and P.A. Taylor, A simple, segmented prism model of tidal mixing in well-mixed estuaries. Estuarine and Coastal Marine Science, 1973. 1(4): pp. 411-418.

[12] Das, A., D. Justic, and E. Swenson, Modeling estuarine-shelf exchanges in a deltaic estuary: Implications for coastal carbon budgets and hypoxia. Ecological Modelling, 2010. 221(7): pp. 978-985.

[13] Shen, J., S.C. Sun, and T.P. Wang, Development of the fecal coliform total maximum daily load using Loading Simulation Program $\mathrm{C}++$ and tidal prism model in estuarine shellfish growing areas: A case study in the Nassawadox coastal embayment, Virginia. Journal of Environmental Science and Health Part a-Toxic/Hazardous Substances \& Environmental Engineering, 2005. 40(9): pp. 1791-1807.

[14] Sheldon, J.E. and M. Alber, The calculation of estuarine turnover times using freshwater fraction and tidal prism models: A critical evaluation. Estuaries and Coasts, 2006. 29(1): pp. 133-146.

[15] Desai, A.M. and H.S. Rifai, Variability of Escherichia coli Concentrations in an Urban Watershed in Texas. Journal of Environmental EngineeringAsce, 2010. 136(12): pp. 1347-1359.

[16] Bowie, G.L., et al., Rates, Constants, and Kinetics Formulations in Surface Water Quality Modeling. EPA 660/3-85-040., 1985. USEPA. Athens, GA.

[17] Beaudeau, P., et al., In situ measurement and statistical modelling of Escherichia coli decay in small rivers. Water Research, 2001. 35(13): pp. 3168-3178.

[18] Liu, W., W.P. Chen, and C. Peng, Assessing the effectiveness of green infrastructures on urban flooding reduction: A community scale study. Ecological Modelling, 2014. 291: pp. 6-14.

[19] Liu, Y., V.F. Bralts, and B.A. Engel, Evaluating the effectiveness of management practices on hydrology and water quality at watershed scale with a rainfall-runoff model. The Science of the total environment, 2015. 511: pp. 298-308.

[20] Zahmatkesh, Z., et al., Low-Impact Development Practices to Mitigate Climate Change Effects on Urban Stormwater Runoff: Case Study of New York City. Journal of Irrigation and Drainage Engineering, 2015. 141(1). 